\title{
Fronteiras da gestão: os conflitos ambientais das atividades portuárias*
}

ICARO A. da CunHa**

S UMÁRIO: 1. Introdução; 2. Portos e jogos de conflito ambiental; 3. Empresas, meio ambiente e negócios: em questão, a reputação; 4. Administrando as influências do porto no território; 5. Marcas sobre o ambiente: interferindo nas oportunidades de utilização dos recursos comuns; 6. A vida dos portos e a vida do estuário: a questão da dragagem; 7. Tópicos para a gestão ambiental do porto de Santos; 8. Limites da governança ambiental: as falhas de gestão e as perdas de energia; 9. Agenda ambiental portuária local como caminho para um plano de gestão pactuado; 10. Possibilidades de ganhos mútuos numa agenda ambiental para os portos.

Summary: 1. Introduction; 2. Ports and environmental conflict games; 3. Companies, environment and business: in question, the reputation; 4. Managing the influences of the port in the territory; 5 . Marks on the environment: interfering in the opportunities to use common resources; 6 . The life of the ports and the life of the estuary; 7 . Topics for the environmental management of the port of Santos; 8. Environmental governance limitations: management failures and energy losses; 9. Local Environmental agenda for ports as a way for an environmental management plan based on consensus; 10. Possibilities for mutual gains in an environmental agenda for ports.

PALAVRAS-CHAVE : gestão ambiental portuária; negociação ambiental.

KEY WORDS : port environmental management; environmental negotiation.

Os portos são objeto recente de atenção da política ambiental brasileira. Por seu papel indutor de transformações territoriais em ampla escala, as ativida-

* Artigo recebido em dez. 2005 e aceito em ago. 2006.

** Sociólogo. Doutor em saúde ambiental pela USP. Professor-assistente do Mestrado em Gestão de Negócios da Universidade Católica de Santos (Unisantos). Endereço: Rua Carvalho de Mendonça, 144 — Vila Mathias _ CEP 11070-906, Santos, SP, Brasil. E-mail: icarocunha@unisantos.br. 
des portuárias têm dado origem a inúmeros conflitos ambientais. As dificuldades das decisões de licenciamento ambiental refletem a incorporação tardia da gestão ambiental pelo setor e limitações das agências de meio ambiente, com destaque para a desarticulação entre planejamento e controles ambientais. A agenda ambiental portuária surge como iniciativa voltada a promover planos de gestão pactuados entre os atores locais.

\section{Management frontiers: environmental conflicts in port activities}

Only recently have the Brazilian ports been a concern of environmental policy. Due to the large-scale territorial changes it induces, this activity has been associated with many conflicts. Difficulties for decisions about environmental permits related to ports are a result of the belated adoption of environmental management by the sector, especially due to the disarticulation between environmental planning and control. The environmental agenda for ports has been an initiative for establishing management plans based on consensus.

\section{Introdução}

Com o apoio da Fundação de Amparo à Pesquisa do Estado de São Paulo, vem sendo desenvolvido um trabalho de pesquisa sobre as iniciativas de gestão ambiental em área portuária, na modalidade políticas públicas. Em parceria com a Companhia de Tecnologia de Saneamento Ambiental e a Companhia Docas do Estado de São Paulo, está sendo construída uma agenda ambiental com incorporação de procedimentos de negociação de conflitos, voltada ao porto de Santos. A metodologia de pesquisa inclui levantamentos por entrevistas, coleta de documentos oficiais e relatórios ambientais, acompanhamento de noticiário, realização de oficinas de negociação ambiental, registros de observação participante nos trabalhos de desenvolvimento da agenda ambiental.

Este artigo apresenta dados retirados desse projeto, que mostram os problemas ambientais ligados ao porto de Santos. A discussão relaciona avanços na gestão ambiental dos negócios, para construir boa reputação ambiental para as empresas.

A situação em um estágio incipiente de incorporação dos portos na política ambiental brasileira, serve como base para entender as dificuldades e os conflitos que envolvem os usuários dos recursos comuns afetados por esta atividade. Um aspecto relevante para entender as dificuldades do licenciamento ambiental dessas atividades está nas limitações de desempenho das agências ambientais públicas, em especial na falta de uma gestão que faça uso integrado dos instrumentos disponíveis em nossa ordem jurídica.

Diante dos impasses surgidos nessa dinâmica, uma agenda baseada em reconhecimento de ganhos mútuos associados a metas graduais de qualidade ambiental pode agregar valores importantes para os negócios portuários, já 
que o padrão de gestão ambiental começa a ser um fator de influência na competição pelas cargas, entre os diferentes portos.

\section{Portos e jogos de conflito ambiental}

Canais por onde trafegam os navios que chegam a um porto são, do ponto de vista da atividade portuária, infra-estrutura técnica. Essas mesmas águas podem ser utilizadas para a pesca, sendo reconhecidas dessa forma como um ecossistema provedor de recursos. Outros atributos de qualidade do mesmo espaço podem ser o que conta para serviços turísticos ali localizados.

Diferenças de significados e percepções dos conjuntos naturais e construídos estão na base dos conflitos socioambientais, aqui entendidos como disputas entre grupos humanos que utilizam de formas distintas os recursos do ambiente (Barragán Muñoz, 1995; Little, 2001).

Os conflitos socioambientais são fenômenos complexos, envolvendo o mundo biofísico e seus ciclos naturais, a teia de relações sociais numa dada formação histórica, e as interações entre ambos. São freqüentes os conflitos relacionados aos impactos ambientais de umas atividades sobre as outras; ou os que se configuram como disputas pela utilização dos mesmos recursos. Registram-se também conflitos em torno do uso de conhecimentos ambientais (Little, 2001).

A administração dos conflitos visando sua resolução por via pacífica pode apoiar-se na abordagem dos ganhos mútuos, que propõe a ultrapassagem de um padrão de jogos de soma zero, aqueles em que um lado ganha e o outro perde, e os resultados positivos e negativos se anulam no balanço total. Em jogos de conflitos, onde interagem diferentes atores sociais com interesses diversos porém legítimos, a construção de entendimentos depende da capacidade dos jogadores de explorarem as necessidades dos demais, identificando zonas de convergência com as suas próprias demandas, sobre as quais podem ser construídas plataformas para acordos (Susskind e Field, 1997; Susskind et al., 2000).

A política ambiental brasileira dá um tratamento técnico e normativo aos seus diversos temas, faltando-lhe ainda a incorporação de um repertório satisfatório de procedimentos para resolução de conflitos de forma negociada (Leis, 1999). O tempo exageradamente longo que tomam as decisões da burocracia ambiental sobre pedidos de licença é uma das manifestações mais evidentes desse fenômeno, tendo recentemente o presidente da República, em visita ao porto de Santos, feito um apelo por um pacto entre a autoridade portuária e o órgão ambiental de controle, pois torna-se difícil para o governo priorizar os in- 
vestimentos para ampliação da capacidade de movimentação de cargas, sem resolver as pendências em relação aos regulamentos ambientais.

Os portos brasileiros são objetos tardios de políticas ambientais. Ao mesmo tempo que os objetivos de incremento do comércio exterior dão urgência a investimentos de melhoria, obras nas vias de acesso, dragagens, projetos de expansão das instalações esbarram na falta de regularidade ambiental. O Rio Grande é o único porto, dos 11 que estão na Agenda Portos do governo federal para receber aporte de recursos, que conta com uma licença de operação junto ao Instituto Brasileiro de Meio Ambiente e Recursos Naturais Renováveis (Ibama).

As situações de conflito ambiental referentes às operações portuárias representam desafios para todos os segmentos afetados, envolvendo um leque extraordinário de agências governamentais com algum tipo de atribuição de controle, a administração do porto, os governos locais, grupos da população que utilizam — produtivamente ou não — os recursos ambientais em que o porto interfere. Portos paulistas influenciam direta ou indiretamente conjuntos definidos como patrimônios nacionais, a zona de costa e a Mata Atlântica - além, evidentemente, dos espaços marinhos enquadrados nas convenções internacionais que regulam os usos dos oceanos. Grupos locais que se mobilizem em reação a projetos específicos podem vir a contar com boas redes de solidariedade.

Essas situações de conflito são campos de interesse singular do ponto de vista da evolução das estratégias ambientais empresariais, já que colocam em xeque linhas de ação autocentradas, chamando necessariamente à interação com instituições e com os grupos do entorno. Por diferentes razões, o desempenho dos gestores das empresas deve estar à altura do potencial de repercussão das decisões, que pode ultrapassar em muito os públicos regionais.

\section{Empresas, meio ambiente e negócios: em questão, a reputação}

Reconhecido como uma referência quando o assunto é competitividade empresarial, Michael Porter também ocupa um posto de destaque quando se discute a empresa e o meio ambiente. Em co-autoria com Van der Linde no artigo "Verde e competitivo" apresentou a idéia que o título bem sugere: tornando-se verde, ou seja, incorporando a gestão ambiental em seus procedimentos, a empresa pode melhorar seu desempenho nos negócios. A observância de requisitos ambientais leva a usar menor quantidade de recursos, evitar desperdícios, enfim, traz uma série de desdobramentos que são também aumentos de eficiência econômica (Porter e Van der Linde, 1999). 
Trata-se de uma reflexão sobre a administração das organizações empresariais, que corrobora o que diferentes autores de correntes engajadas na produção sobre meio ambiente e desenvolvimento - como é o caso de Sachs - afirmam insistentemente há muito tempo: os recursos ambientais são recursos econômicos, não podendo ficar fora das contas da economia, relegados ao espaço das externalidades. Os regulamentos ambientais, orientados pela busca da internalização das externalidades, geram inovações de gestão nas empresas; e também inovações no pensamento sobre o que é uma boa gestão.

Muitas empresas já vão além do atendimento aos regulamentos. Surgem diferentes modelos de gestão ambiental empresarial, cuja base incorpora o sistema de gestão ambiental proposto pelos procedimentos ISO $14000-$ padrão pelo qual já se pode esperar a ultrapassagem da mera conformidade legal, pela via da melhoria contínua - mas que ambicionam, eventualmente, resultados ainda mais avançados. Como, por exemplo, atingir o patamar da ecoeficiência, que poderia de certa forma ser entendida como uma idéia estendida do raciocínio de Porter reproduzido anteriormente: produzir mais, consumindo menos recursos. No caso, reduzindo a demanda por serviços ambientais, pela retirada de materiais, água, energia da natureza, e também por meio de redução na geração de resíduos a serem assimilados pelo ambiente (Almeida, 2002; Barbieri, 2004).

A empresa pode contabilizar ganhos econômicos ao utilizar menos natureza, pois finalmente percebe-se que há limites do uso dos bens antes considerados livres e ilimitados. Situações de escassez e colapsos artificialmente produzidos tornam inescapável essa percepção, que se desdobra em políticas que passam a "cobrar" pelo uso dos recursos ambientais - como é o caso da água - e também em atitudes críticas de consumidores e outros stakeholders relevantes.

Outro tipo de ganho diz respeito à imagem. A organização que, em seu gerenciamento, incorpora a atenção aos grupos de interesse com que se relaciona, irá participar de jogos de negociação de conflitos onde o objetivo geral é a construção de aceitação, legitimidade para seus negócios (Andrade, 2000). Tal aceitação influencia não apenas as decisões de consumo, mas também outras relações que se estabeleçam, como as de vizinhança.

Decisões como os licenciamentos ambientais são indissociáveis da imagem que cada empresa consegue construir na sociedade, já que nossa política ambiental tem mecanismos participativos que levam as agências de governo a se preocupar com a opinião do público sobre as suas decisões. Hoje, no Brasil, quem dá as licenças ambientais é a sociedade, diz Almeida (2001), para 
quem no campo do meio ambiente já não se vive o tempo da predominância das ações de comando e controle por parte do governo.

Essa etapa deu lugar a um equilíbrio tripartite, em que atuam empresas, governo e grupos da sociedade, um ambiente em que a imagem dos empreendimentos passa a ser decisiva para sua viabilidade. A reputação ambiental torna-se um ativo intangível da empresa (Almeida, 2002).

\section{Administrando as influências do porto no território}

O advento da gestão ambiental portuária no Brasil coloca em evidência a administração de atividades com forte capacidade de transformação dos espaços regionais em que se inserem. A diretriz fundadora do presente movimento de política ambiental para os portos é a Agenda ambiental portuária, documento oriundo da Comissão Interministerial para os Recursos do Mar (Cirm), no final da década de 1990. Ali são listados exemplos dos potenciais impactos que os portos ocasionam: os resultantes das atividades de dragagem para aprofundamento ou manutenção dos canais de navegação, as mudanças de linha de costa como conseqüências de obras de implantação de infra-estrutura, a supressão de trechos de ecossistemas biologicamente importantes como manguezais, a geração de resíduos e efluentes, os acidentes ambientais com derramamento de cargas tóxicas, o transporte de espécies exóticas de um outro lado do planeta nas águas de lastro de navios (Cirm, 1998).

A Agenda ambiental portuária representou a articulação entre o programa de gerenciamento costeiro; a política federal, que desde os anos 1980 vem construindo as bases para uma ação de ordenamento da ocupação da costa; e a política de modernização dos portos brasileiros, que sob a égide da integração das economias em escala global e suas demandas por velocidade no trânsito de mercadorias, redefiniu as relações entre poderes públicos e agentes privados nos portos e alterou profundamente as relações de trabalho, respondendo entre outros fatores às mudanças tecnológicas da era do contêiner (Junqueira, 2002). O documento da Cirm dá parâmetros para o comportamento ambiental dos portos e prevê novas funções de coordenação nesse campo para as autoridades portuárias.

Os portos são elos das cadeias logísticas que integram fluxos de transporte de mercadorias entre regiões diferentes, gerando influências que se estendem muito além de seus locais de instalação. Barragán Muñoz (1995) diz que os portos são infra-estruturas estruturantes, determinando a dinâmica territorial à sua volta, condicionando a construção de estradas, ou a configuração das malhas urbanas. 
As cidades costeiras que abrigam portos devem, em geral, suas histórias a essa condição, guardando inclusive bens arquitetônicos que documentam diferentes etapas históricas do "namoro do homem com a natureza". Patrimônios naturais e construídos na zona de costa brasileira vêm sofrendo as pressões de um processo de (re)ocupação do território, que teve lugar nas décadas recentes (Moraes, 1999). Os portos são um dos fatores de dinamização desse processo, sendo pólos de atração de investimentos produtivos e mão-de obra, induzindo ainda à ampliação das facilidades de acesso rodoviário que impulsionam movimentos da economia imobiliária nos espaços de ocupação ainda rarefeita no litoral.

As relações porto-cidade mudaram ao longo da história, alternando períodos de integração com outros de isolamento e disputa de espaço. Em períodos recentes, muitas cidades redescobriram áreas portuárias, utilizando-as em estratégias de requalificação urbana, onde se combinaram projetos de turismo e lazer a outras finalidades econômicas, com sucesso (Meyer, 1999). A integração dos conjuntos urbanos às frentes de água é um dos elementos importantes dessas políticas que procuram dar respostas positivas aos tempos em que os lugares entram em competição pela localização de investimentos capazes de dinamizar as economias locais (Ferreira e Castro, 1999).

Tais alternativas de articulação entre espaços físicos e diferentes técnicas, que podem ter um peso estratégico do ponto de vista da geração de oportunidades para o conjunto das populações das cidades que abrigam portos, devem agora defrontar-se com tensões originadas pelas medidas de segurança planejadas para a lide com a ameaça de ações terroristas. O código de segurança adotado em escala internacional a partir de proposições de autoridades norte-americanas determina todo um controle sobre os acessos aos espaços portuários, que reintroduz a questão do confinamento (Grota, 2006).

\section{Marcas sobre o ambiente: interferindo nas oportunidades de utilização dos recursos comuns}

Os conflitos territoriais dos portos ligam-se fortemente à demanda por espaços para implantação de pátios de cargas. O uso generalizado do contêiner como solução logística a serviço da agilidade dos fluxos de transporte multiplica a voracidade com que os portos demandam espaços de retroárea para os cais de atracação.

O contêiner determina a substituição da mão-de-obra para a movimentação de cargas, pelo uso de máquinas. Grandes ship loaders, movimentados com apoio de programações informatizadas, carregam em poucas horas navios de grande porte. Aumento da profundidade dos canais e dos espaços para 
depósitos de cargas são intervenções espaciais superlativas de apoio às atividades econômicas que reduzem seu potencial de geração de oportunidades de trabalho. Cidades portuárias tradicionais, como Santos, enfrentam crises de desemprego tecnológico: na década de 1990, enquanto esse porto expandia sua movimentação em 50\%, a massa salarial associada reduzia-se no mesmo volume (Rodriguez e Vaz, 2001).

Registram-se assim tendências contraditórias em relação à ampliação da intervenção das atividades portuárias na rede urbana e nos conjuntos naturais, que são recursos de uso comum essenciais ao bem-estar e à sobrevivência da população que, em seu conjunto, não pode tirar seu sustento da economia dos portos. As intervenções econômicas alteram e degradam a qualidade do ambiente, dentro do padrão técnico desse momento, sem garantir o atendimento às necessidades básicas dos diferentes grupos da sociedade. Trata-se de um padrão sem sustentabilidade ecológica e social, que não aloca eficientemente os recursos econômicos (Comissão Mundial Sobre Meio Ambiente e Desenvolvimento, 1988; Sachs, 1993 e 2004). Outros potenciais de aproveitamentos econômicos, que poderiam incluir socialmente esses grupos humanos, chocam-se com aqueles usos que provocam a ultrapassagem dos limites ambientais.

Ostrom e MacKean assinalam a dificuldade das sociedades modernas em lidarem com recursos que deveriam ser gerenciados para dar suporte a benefícios para uma coletividade. Mares e florestas responsáveis pela produção de água são conjuntos que oferecem serviços ambientais à sociedade e que dependem de que seja respeitada a sua indivisibilidade. As intervenções orientadas por racionalidades de cada agente econômico não são capazes de administrar seu efeito conjunto e obter um padrão equilibrado de utilização. As autoras remetem ao exemplo de sociedades tradicionais, que praticam uma propriedade compartilhada sobre determinados conjuntos de recursos como áreas de pesca ou florestas —, e dessa forma implantam regulamentos de uso que garantem sua renovação, respeitando os limites ecossistêmicos. Planos diretores e zoneamentos seriam exemplos de gestão moderna que se aproximam dessa idéia de uma propriedade compartilhada sobre determinados conjuntos comuns, dando rumos alternativos a conflitos de usos (McKean e Ostrom, 2001).

\section{A vida dos portos e a vida do estuário: a questão da dragagem}

Na Baixada Santista, além das atividades portuárias reunidas no porto de Santos, ocorrem ainda aquelas que utilizam o chamado porto da Cosipa, em 
Cubatão. A unidade ambiental diretamente impactada por essas atividades portuárias é o sistema estuarino santista, um complexo de manguezais, canais, rios, alagados e bancos de lodo limitados ao norte pelo município de Bertioga (bacia do rio Itapanhaú) e ao sul por Praia Grande e São Vicente (bacias dos rios Branco, Mariana e Piabaçu). Embora fortemente alterada, em especial pela poluição oriunda de Cubatão em anos anteriores, a região é uma área importante do ponto de vista da biodiversidade, principalmente nas porções mais bem conservadas nas proximidades de Bertioga. Ali, a ocorrência de grande número de espécies de avifauna leva os estudiosos a classificarem a Baixada Santista como um ponto de importância singular para as aves migratórias no Sudeste brasileiro (Olmos, Silva e Martuscelli, 1996; Miranda, 1996; Rodrigues et al., 1996).

Estuários são áreas de grande produtividade biológica, verdadeiras "fábricas de vida" que guardam papel central na cadeia alimentar marinha. São espaços de reprodução e crescimento de várias espécies, e dos quais depende a produção pesqueira em vastas áreas. O reconhecimento do papel básico desses e outros ecossistemas costeiros para a renovação dos recursos do mar faz com que a política ambiental dedique especial atenção ao tratamento dado a esses espaços.

O grande aporte de sedimentos nos canais do estuário santista demanda dos portos uma atividade periódica de dragagem de manutenção. O monitoramento ambiental feito ao longo dos anos, embora demonstrando melhoria em vários aspectos da poluição do estuário, indicou, em finais da década de 1990, contaminação no material dragado, levando a Companhia de Tecnologia de Saneamento Ambiental (Cetesb), agência paulista de combate à poluição, a tomar medidas de controle ambiental em relação à atividade de dragagem. As restrições são mais severas em relação à bacia de evolução da Cosipa, onde os sedimentos apresentavam presença de hidrocarbonetos policíclicos aromáticos, metais pesados e compostos fenólicos (Cetesb, 2001).

A situação desafia empresas e agências ambientais a um equacionamento que combine respeito aos parâmetros ambientais e expansão das atividades econômicas. Evidenciaram-se nesses episódios limitações no campo da gestão ambiental pública, como a falta de padrões ambientais nacionais para sedimentos, que só em 2004 seriam estabelecidos por nova resolução do Conselho Nacional de Meio Ambiente (Conama).

O porto de Santos seria autorizado a dragar, já que a poluição, certamente vinculada em boa parte aos despejos industriais em anos do passado na região de Cubatão, não é tão acentuada na região do canal de navegação diretamente ligada a esse porto, mais próximo à baía de Santos. O terminal da Cosipa partiu para elaborar alternativa mais complexa - e mais cara - de gerenciamento da dragagem e disposição dos materiais, que ainda busca licenciamento. Santos pôde retomar a dragagem com esquemas de gestão mais 
sofisticados que os tradicionalmente praticados, que incluem uma rotina de retirada e despejo de materiais em espaços alternados e monitoramento constante, com dados fornecidos online para a Cetesb.

\section{Tópicos para a gestão ambiental do porto de Santos}

O "Estudo de conflitos legais e socioambientais para ocupação do solo em área destinada à atividade portuária", desenvolvido pela Superintendência de Meio Ambiente da Codesp e encaminhado em 2006 ao Departamento de Avaliação de Impactos Ambientais da Secretaria Estadual de Meio Ambiente, tem informações sobre ocupação do solo e cobertura vegetal, áreas de preservação permanente, patrimônio histórico e arqueológico, fontes de poluição, atividades de pesca artesanal, zoneamentos municipais. Coteja o atual Plano de Desenvolvimento e Zoneamento do porto com esses dados e apresenta uma carta-síntese de conflitos socioambientais.

Os conflitos identificados incluem aspectos de localização de projetos de expansão, em casos de competição pelo espaço com comunidades instaladas de forma mais ou menos irregular - como no Sítio Conceiçãozinha em Guarujá, margem esquerda do porto, onde uma população que inclui pescadores tradicionais disputa a frente de água na vizinhança do terminal da Cargill Agrícola S.A.

Há casos em que o conflito se refere à destinação de preservação para as áreas pretendidas para implantação de terminais, como aquelas em que há trechos de manguezais, vegetação protegida pelo Código Florestal.

O diagnóstico identifica superposições entre o canal do porto e rotas de pesca artesanal. Esse canal, no trecho do estuário de Santos, o canal de Piaçagüera e a região de confluência dos canais de Bertioga e Piaçagüera, nas proximidades da ilha Diana, fazem parte das rotas de cinco comunidades de pescadores pesquisadas.

Conflitos de operação envolvem casos de poluição - como as emissões aéreas do terminal de granéis sólidos no terminal de fertilizantes, ou a perda de produtos ao longo das vias de acesso. Nessa categoria, o estudo inclui as instalações em que há riscos de acidentes ambientais cujas conseqüências podem afetar moradores das vizinhanças. Os cenários acidentais identificados nos programas de gerenciamento de riscos conduzidos pela Cetesb incluem, em certos casos, possibilidades como vazamentos de produtos tóxicos, incêndios de grandes proporções ou explosões, envolvendo algumas das instalações perigosas. Na Baixada Santista, 16 terminais químicos e algumas instalações que têm outras finalidades mas utilizam produtos perigosos podem se enquadrar nessa categoria (Cunha, 2005). 
São identificados, dentro da área de abrangência das operações portuárias, conjuntos naturais, como o Largo de Santa Rita ou o Largo do Caneu, que mantêm boas condições para manutenção de vida marinha e avifauna, ou para reprodução de peixes e crustáceos, servindo de ponto de pesca artesanal.

No centro de Santos, as disparidades porto-cidade se dão em sítio histórico, incluído em projetos de requalificação urbana. O diagnóstico assinala um "estrangulamento" do porto pela cidade nessa área, onde há todo um conjunto de bens protegidos pelo tombamento.

Outro exemplo de conflito porto-cidade se dá no corredor de exportações, vizinho ao bairro da Ponta da Praia, ante os incômodos das emanações de odores e à atração de pragas urbanas como pombos e ratos. No conjunto, são mapeados 11 conflitos de expansão portuária e 12 conflitos de operações.

A matriz de fontes de poluição reuniu dados de numerosos pontos, em 17 faixas de cais. Incluem-se no levantamento diferentes tipos de poluição, distribuídos também por sua freqüência. Fontes acidentais são, por exemplo, associadas a queda de contêiner seguida de vazamento ou exposição de produto químico; a rompimento ou vazamento de mangote no carregamento de suco cítrico; ou vazamento de amônia em sistema de refrigeração.

Emissões de difícil controle são vazamentos de navios atracados, emissões clandestinas de esgotos ou despejo de resíduos ou águas de lastro. Fontes sazonais estão associadas a carregamento e descarregamento de produtos, em especial granéis sólidos como soja, trigo, ou então disposições de resíduos.

Fontes permanentes ainda com controles ineficazes podem ser solos contaminados, píer ou armazém com carregamento e descarregamento contínuo. Todas essas categorias podem ser agressivas, orgânicas ou inertes.

Várias dessas situações têm soluções sendo implantadas, enquanto outras ainda vivem uma etapa de planejamento das ações de gestão (Consultoria Paulista, 2006).

Essas informações se somam a outras, já costumeiramente divulgadas, como os avanços em certificação ambiental dos diferentes terminais, que no conjunto do porto já englobam 19 sistemas de gestão orientados pelas normas da série ISO 14000.

\section{Limites da governança ambiental: as falhas de gestão e as perdas de energia}

Uma das dificuldades mais sérias para o equacionamento da gestão ambiental do porto de Santos é o número de agências governamentais com atribuições relacionadas a esse campo, e a falta de articulação entre essas burocracias. Num 
seminário desenvolvido pela autoridade portuária (Codesp) e a Universidade Católica de Santos, em 2003, participaram as seguintes instituições:

、 Ministério do Meio Ambiente - Coordenação de Gerenciamento Costeiro;

、 Ibama (Instituto Brasileiro de Meio Ambiente e Recursos Naturais Renováveis);

v Anvisa (Agência Nacional de Vigilância Sanitária);

v Redec I 2 (Coordenadoria Regional de Defesa Civil);

v Marinha (Capitania dos Portos);

- Secretaria Estadual de Meio Ambiente;

v Daia (Divisão de Avaliação de Impactos Ambientais da Secretaria Estadual de Meio Ambiente);

v DEPRN (Departamento Estadual de Proteção de Recursos Naturais);

v Coordenação de Planejamento - Programa de Gerenciamento Costeiro;

v Cetesb (Companhia de Tecnologia de Saneamento Ambiental);

v Prefeitura de Santos - Secretaria de Meio Ambiente;

v Prefeitura de Guarujá - Secretaria de Meio Ambiente;

v Agência Metropolitana da Baixada Santista;

v Secretaria Municipal de Planejamento de Guarujá e Secretaria Municipal de Planejamento de Santos;

v Comitê de Bacias Hidrográficas da Baixada Santista;

v Conselho de Patrimônio Histórico da Prefeitura de Santos.

Vale ressaltar também a presença do Ministério Público, intervindo freqüentemente sobre os campos de ação de todos esses órgãos, zelando pelo respeito estrito à legislação. A ocorrência freqüente de conflitos e as queixas associadas provocam numerosas intervenções da promotoria, como foi o caso dos controles sobre a atividade de dragagem já descritos, quando um dos fatores da crise foi justamente uma reclamação quanto à contaminação da praia do Guarujá pelo retorno do material dragado despejado no mar.

O estabelecimento de uma gestão ambiental integrada e eficaz em relação ao porto de Santos é uma meta na direção da qual se interpõe uma tradição de burocracias ambientais que foram criadas em paralelo e por vezes com 
atribuições superpostas. Os órgãos governamentais de meio ambiente reúnem agrupamentos de especialistas, faltando, via de regra, a instância articuladora da política ambiental global (ver Guimarães, 1986; Ferreira, 1997).

Os instrumentos de gestão ambiental disponíveis em nossa ordem jurídica, basicamente os definidos na Lei $\mathrm{n}^{\mathrm{O}}$ 6.938/81, dão oportunidade de uma gestão abrangente. O planejamento ambiental com uso do zoneamento ecológico e econômico permite combinar em propostas de usos futuros as atividades econômicas e os assentamentos humanos com as características dos ambientes e os limites ecológicos. Os controles ambientais pela via do licenciamento e da fiscalização são os meios para enquadrar os empreendimentos nas diretrizes e regulamentos estabelecidos. As unidades de conservação prestam-se à proteção e uso prudente dos recursos da biodiversidade. A educação ambiental é instrumento para conquistar a adesão voluntária dos diferentes segmentos a novos comportamentos mais responsáveis. As várias formas de monitoramento servem para avaliar a evolução de qualidade ambiental e os erros e acertos da política.

Num sistema de meio ambiente, que articula e define as responsabilidades das diferentes instâncias administrativas - como é o sistema estabelecido na referida lei —, os instrumentos de gestão devem ser usados de forma complementar. A gestão ambiental está no conjunto e não em cada parte. Com o advento dos sistemas de gestão ambiental das empresas, um novo elo de uma cadeia potencialmente virtuosa foi disponibilizado. Mas a verdade é que raramente se encontram experiências em que um setor da burocracia ambiental trabalha sintonizado com o outro, exercitando a complementaridade que torna inteligentes os muitos requisitos legais com que se defrontam os empreendimentos econômicos.

A demanda mais urgente nesse sentido é a integração entre planejamento e controle. Os instrumentos de controle são conflituosos, pois licenças ambientais são atos administrativos vinculados: a licença é um direito do solicitante e deve ser dada, se o empreendimento em foco cumprir a lei; ou a licença não pode ser dada, caso se esteja fora dos parâmetros legais (Machado, 1991). Negociações sobre diretrizes são possíveis e necessárias, mas se combinam com as etapas de planejamento ambiental, quando não existe a pressão dos prazos de investimentos, de empréstimos, de mercado, legais para a tramitação de licenças, e para audiências publicas. O tempo da decisão torna-se uma ameaça para todos, no processo de licenciamento, quando não há diretrizes claras e previamente discutidas na sociedade.

A desarticulação da função de controle (licenciamento e fiscalização) com o planejamento ambiental é uma falha de gestão na base dos conflitos 
em torno do licenciamento ambiental, cuja manifestação mais evidente é o tempo excessivamente longo dos processos decisórios.

Contribui para esse fenômeno um outro aspecto do contexto de conflito, o medo de decidir que assalta os técnicos de governo, preocupados com os dispositivos da lei de crimes ambientais que permitem seu próprio enquadramento em caso de decisões descuidadas. As rotinas de controle não contam com canais para as pressões legítimas dos diferentes setores da sociedade que deveriam ser destinadas para a discussão de planos e diretrizes - e essas pressões alimentam a entropia dos processos.

Esse quadro geral da política ambiental brasileira está presente na realidade do maior porto do Brasil, que passa a ser "descoberto" como foco de atenção para a gestão ambiental, assim como o resto do conjunto de portos do país. Atividades de grande porte, extraordinários complexos produtivos que transformam o território em larga escala, obviamente apresentam enorme discrepância em relação aos regulamentos ambientais à margem dos quais se movimentaram até muito recentemente. Mas, seguindo o padrão corrente na política ambiental brasileira, o instrumento de gestão de que se lança mão é o controle.

Recentemente, o porto de Santos atualizou seu PDZ (plano de desenvolvimento e zoneamento). Não contou com diretrizes prévias para balizar seus projetos de novas áreas de atracação, um dos aspectos mais relevantes de conflito, já que os espaços regionais têm - como assinalado no diagnóstico da Codesp - forte presença de conjuntos destinados pela lei à preservação: os manguezais. Embora o estado de São Paulo conte com um Programa de Gerenciamento Costeiro, iniciado no final dos anos 1980, até aqui a Baixada Santista não dispõe de um ZEE (zoneamento ecológico e econômico). Essa ausência de diretrizes espaciais torna mais difícil cada análise de impacto ambiental para novos empreendimentos. Não havendo parâmetros regionais, metas de qualidade, sobre que base os decisores trabalharão?

\section{Agenda ambiental portuária local como caminho para um plano de gestão pactuado}

O Ministério do Meio Ambiente (MMA) e a Antaq - Agência Nacional de Transportes Aquaviários - começaram a promover o desenvolvimento e implantação de agendas ambientais locais dos portos. A orientação proposta pelo MMA indica que as agendas deverão ser desenvolvidas como planos de gestão pactuados entre as administrações portuárias, os órgãos ambientais, os 
governos locais, grupos da população afetados pelas operações e/ou interessados na pauta de discussões.

Os conflitos ambientais tornaram-se fatores de paralisia em vários campos da economia brasileira, inclusive os portos. De pouca utilidade tem se revelado o repertório tradicional dos grandes atores econômicos, que costumeiramente batem na tecla de atribuir as crises ao radicalismo de militantes e técnicos de agências ambientais, e com isso pouco obtêm, além da redução de sua credibilidade.

Em lugares como Santos, a discussão da política ambiental não se dá estritamente em torno da preservação de ambientes naturais paradisíacos e intocados, cuja pureza se quer manter. O que gera impasses é o grau a que chegou a degradação ambiental: o que paralisa a dragagem é a poluição já existente no estuário, e não a idéia de preservar a natureza. A atividade portuária tem como obstáculo uma poluição gerada por diversas fontes, num passado em que a ecopolítica do Estado brasileiro se organizava em torno da idéia de que a poluição é o preço do progresso (Guimarães, 1986). Hoje a atividade portuária tem de arcar com esse preço para liberar os canais de navegação.

A agenda ambiental portuária abre uma oportunidade para que os negócios portuários se insiram num outro jogo de negociação de conflitos, em que os objetivos de melhoria da qualidade ambiental e as responsabilidades sejam compartilhados entre diversos atores regionais. Novas atitudes podem ser construídas por meio de estratégias apoiadas na busca de relações de confiança, em que um primeiro passo é o reconhecimento da real situação ambiental do porto e sua área de influência. A partir daí, pode-se avançar na discussão das tarefas necessárias para alcançar mudanças positivas, os prazos e os investimentos que separam a região dessas metas de qualidade.

Trata-se de tarefa trabalhosa e complexa para um porto como Santos, por onde flui uma fatia de cerca de $25 \%$ do comércio exterior do país, ligando um número enorme de negócios localizados em diferentes regiões, num desafio logístico gigantesco. Em contraponto a essa complexidade, o porto conta com uma área de gestão ambiental ainda incipiente, cuja implantação se iniciou no final dos anos 1990, não sendo reconhecida em seu peso estratégico pela organização da autoridade portuária em que se insere e por isso tendo ainda sérias dificuldades para participar nas decisões gerenciais, em relação a outros departamentos da estatal que administra o porto e junto às empresas que nele atuam.

A agenda ambiental local é trabalhada com a idéia de que a incorporação de novos padrões de gestão ambiental deve ser vista como valor agregado aos negócios portuários. A difusão dos sistemas de gestão ambiental empresarial que trabalham com a diretriz de administrar o ciclo de vida dos produtos começa a gerar demandas para os terminais portuários, inseridos em cadeias 
logísticas que devem demonstrar sua conformidade com os respectivos regulamentos e as boas práticas ambientais.

Essa idéia tem amparo no mundo dos negócios portuários. No trabalho de pesquisa sobre gestão ambiental portuária, já tem sido possível confirmar junto a gestores de portos como Santos, Rio Grande e São Sebastião que os responsáveis por grandes cargas hoje definem a opção por operar num ou noutro porto seguindo critérios que incluem a verificação do estágio de gestão ambiental e a situação de conformidade legal dos terminais. Embora existam portos brasileiros que fazem concorrência predatória com outros, cobrando tarifas mais baratas por não estarem submetidos a exigências ambientais tão severas - o que é denunciado pelos portos que avançam na implantação dos procedimentos de meio ambiente - essa "vantagem do atraso" perde espaço de mercado, e certamente se tornará um ônus quando iniciativas de cobrança de adequação legal se avolumarem.

\section{Possibilidades de ganhos mútuos numa agenda ambiental para os portos}

No desenvolvimento de fóruns de negociação ambiental, registram-se em grandes linhas comportamentos dentro das seguintes orientações:

v as agências ambientais esperam que as atividades econômicas incorporem os regulamentos ambientais em suas práticas;

$\checkmark$ as empresas esperam que o enquadramento nos regulamentos ambientais respeite as necessidades econômicas e limites de suas atividades;

、 o público espera ser levado em consideração pelos regulamentos e pelas atividades econômicas (Susskind et al., 2000).

Aparentemente simples, tais demandas devem superar a barreira inicial da falta de tradição em construir processos de diálogo para resolver situações de conflito ambiental, incorporando tais mecanismos nas iniciativas de gestão. Contudo, hoje elementos podem ser identificados como motivadores para a construção de processos cooperativos, em que potenciais econômicos dos lugares sejam aproveitados seguindo estratégias estabelecidas por meio de entendimentos geradores de ganhos mútuos.

Em diferentes campos da economia da região de influência de um porto, há importantes razões para esperar benefícios das melhorias de qualidade 
ambiental por parte dessa atividade que é um grande usuário das águas costeiras e das malhas urbanas.

Pode-se observar que a própria atividade portuária vai conferindo viabilidade e interesse econômico a ações de recuperação ambiental. Exemplos de equacionamentos de alguns passivos ambientais são ilustrativos.

No caso do terminal da Cosipa, a empresa divulgou durante as discussões do "Estudo de impacto ambiental" do seu projeto de dragagem do canal de Piaçagüera que esse investimento será US\$ 20 milhões maior do que uma solução convencional de dragagem, para viabilizar um processo com bom controle ambiental. Evidentemente, a economia potencial da utilização do terminal cobrirá o investimento, que fará frente a um passivo acumulado em anos anteriores.

Na área do lixão do porto de Santos, hoje desativado para fins de disposição de resíduos, mas ativo como fonte de poluição do estuário - pela decomposição do material já depositado - , o início de trabalhos para remediação ambiental da área atende a exigências legais e conveniências econômicas, pois trata-se de espaço arrendado para várias empresas, com localização nobre no interior do porto organizado, mas com uso condicionado pela situação de contaminação.

Como essas, outras iniciativas de saneamento ambiental se tornarão convenientes como liberação de potenciais econômicos, a seu tempo. Assim, o saneamento do ambiente e as atividades de gestão ambiental em geral crescerão como alternativas econômicas para trabalhadores e empresas regionais. A despoluição do estuário e a recuperação de áreas degradadas são importantes oportunidades econômicas regionais, que devem ganhar força com o avanço da gestão ambiental portuária.

Pesca e aqüicultura são atividades cujos agentes poderão obter importantes benefícios se conseguirem acesso aos processos de diálogo e negociação. A pesca tem enfrentado duras perdas com a degradação ambiental, o que no estuário de Santos e São Vicente inclui fatores variados, como a poluição industrial e de outras fontes, inclusive o porto; a destruição dos criadouros naturais dos manguezais; a contaminação de organismos como caranguejos e moluscos, capturados para comercialização e para consumo próprio. Pesquisas registram a atividade de 2.700 pescadores artesanais na Baixada Santista (Amorim et al., 2004), localizando-se cerca de $25 \%$ desse total na área interna do estuário, onde são mais afetados pela poluição crônica e, potencialmente, por acidentes que gerem vazamentos de substâncias ambientalmente agressivas.

Outro campo com potencial para expansão de oportunidades de inclusão é o turismo. $\mathrm{O}$ atrativo do binômio sol e praia é um importante fator eco- 
nômico para as cidades litorâneas. A qualidade das águas — e das praias pode incrementar as movimentações do setor, bem como o avanço para um patamar mais equilibrado de ordenamento espacial das atividades, evitandose perdas de valor por fatores como congestionamentos de tráfego de caminhões, vizinhanças com pátios de cargas ou instalações perigosas.

Um gerenciamento ambiental mais avançado na área de influência do porto, contribuindo para a melhoria da qualidade ambiental na região e em especial no estuário, pode expandir os potenciais de aproveitamento turístico sustentável. Turismo ecológico, turismo náutico e turismo cultural são atividades que hoje enfrentam severos limites na costa de São Paulo. Se contribuir para a garantia de usos múltiplos das águas na área de influência do porto, a agenda ambiental portuária será um fator impulsionador desses potenciais, que dispõem da vantagem da proximidade com o mercado, em especial a Região Metropolitana de São Paulo.

Esses exemplos de novas sinergias entre uma economia portuária convertida a padrões de qualidade ambiental e os diversos potenciais econômicos dos recursos comuns da região são elementos que podem ser incorporados nas estratégias de negociação dos atores ligados ao porto. Podem combinar-se aos próprios ganhos com uma evolução nos relacionamentos interinstitucionais para novos patamares de entendimento, que consigam acomodar expectativas e conciliar o ritmo em que a atividade fará essa conversão, com seus resultados econômicos.

A agilidade e a eficácia das agências ambientais fazem parte dos interesses estratégicos do setor portuário. Parte das dificuldades decisórias, como visto, em processos formais de meio ambiente, é decorrência da desarticulação das burocracias ambientais. Às soluções que surjam do trabalho integrado se somarão outras, consequiências do diálogo dos técnicos da área com os gestores portuários, que permitirão acordar procedimentos que de parte a parte criarão condições para uma simplificação das decisões que, na realidade, pode interessar a todos.

A agilização das decisões de meio ambiente depende também do respaldo na sociedade, ou seja, da confiança do público e de setores especializados como o Ministério Público, quanto ao estrito cumprimento dos requisitos ambientais, gerando proteção e segurança aos espaços naturais e construídos.

$\mathrm{O}$ atraso da política ambiental em relação aos portos pode ser entendido com apoio de uma visão histórica; mas é difícil de justificar para muitos. A literatura sobre riscos ambientais e conflitos demonstra que, para o público, os riscos ambientais são percebidos com indignação, especialmente se impostos por atores de grande poder (Hance, Chess, Sandman, 1990; Susskind, 1997). Indignação e falta de confiança, em relação a atores vistos como res- 
ponsáveis por situações de degradação ambiental, podem estar na origem de atitudes agressivas, que se desdobram em processos judiciais e contestações de diferentes tipos.

A transformação do conflito em cooperação para construir soluções ambientais para a complexa realidade dos portos é uma tarefa desafiadora e fundamental para muitos segmentos econômicos que têm operações portuárias. No espelho das águas do estuário, as imagens das marcas se refletem misturadas a resíduos e substâncias perigosas. Estas talvez sejam as marcas do passado, mas sua superação demanda uma forte dose de compromisso, capaz de oferecer razões para que os diferentes públicos se aproximem.

\section{Referências bibliográficas}

ALMEIDA, F. O bom negócio da sustentabilidade. Rio de Janeiro: Nova Fronteira, 2002.

AMORIM, A. et al. Aspectos socioeconômicos da pesca artesanal na região da Baixada Santista. In: CONGRESSO BRASILEIRO DE PESQUISAS AMBIENTAIS E SAÚDE, 4., 2004, Santos. Anais... Santos, 2004.

ANDRADE, J. C. Conflito, cooperação e convenções: a dimensão político-institucional das estratégias socioambientais da Aracruz Celulose S.A. 2000. Tese (Doutorado) — Escola de Administração da UFBA, Salvador.

BARBIERI, J. C. Gestão ambiental empresarial. São Paulo: Saraiva, 2004.

BARRAGAN MUÑOZ, J. M. Puerto, ciudad y espacio litoral em la Bahia de Cádiz. Salamanca: Autoridad Portuária de la Bahia de Cádiz, 1995. diz, 2005.

La gestión de áreas litorales em España y Latinoamérica. Cádiz: Universidad de Cá-

BRASIL. Ministério dos Transportes. Política Ambiental do Ministério dos Transportes. Brasília, 2002.

BRASIL. Ministério do Meio Ambiente. Agenda ambiental portuária - qualidade ambiental e atividade portuária. Brasília, 2005.

CÂMARA PAULISTA DO SETOR PORTUÁRIO. Gestão ambiental no contexto do desenvolvimento regional. Relatório final. São Paulo: Cetesb, 1996a.

—. Memória técnica. São Paulo: Cetesb, 1996b.

CIRM (COMISSÃO INTERMINISTERIAL PARA OS RECURSOS DO MAR). Agenda ambiental portuária. Brasília, 1998. 
COMISSÃO MUNDIAL SOBRE MEIO AMBIENTE E DESENVOLVIMENTO. Nosso futuro comum. Rio de Janeiro: FGV, 1988.

CETESB (COMPANHIA DE TECNOLOGIA DE SANEAMENTO AMBIENTAL). Plano de controle ambiental do porto de Santos - levantamento das fontes poluidoras. Santos: Cetesb, 2000 .

\section{—. Relatório sistema estuarino de Santos e São Vicente. 2001.}

CONSULTORIA PAULISTA. Estudo de conflitos legais e socioambientais para ocupação do solo em área destinada à atividade portuária. Santos, 2006.

CUNHA, I. A. Conflitos ambientais das atividades portuárias e política de gerenciamento costeiro. In: JUNQUEIRA, L. (Org.). Desafios da modernização portuária. São Paulo: Aduaneiras, 2002.

_. Desafios para o gerenciamento de riscos ambientais na Baixada Santista. In: PERDICARIS, A. (Org.). Temas em saúde coletiva. Santos: Leopoldianum, 2005.
— - MOSSINI, E. O estuário de Santos como cenário de negociação ambiental. In: ENANPAD, 2002, Salvador. Anais... Salvador: Associação Nacional de Pós-Graduação e Pesquisa em Administração, 2002.

DIEGUES, A. C. Ecologia humana e planejamento em áreas costeiras. São Paulo: Nupaub/ USP, 1996.

FERREIRA, L. A questão ambiental. Campinas: Boitempo, 1997.

FERREIRA, V. M.; CASTRO, A. Cidades de água - a lenta "descoberta" da frente marítima de Lisboa. In: FERREIRA, V. M.; INDOVINA, F. (Orgs.). A cidade da Expo' 98: uma reconversão da frente ribeirinha de Lisboa? Lisboa: Bizâncio, 1999.

GROTA, A. Gestão ambiental no porto de Santos. 2006. Monografia (MBA em gestão ambiental costeira e portuária) — Universidade Católica de Santos, Santos.

GUIMARÃES, R. P. Ecopolitics in the third world: an institutional analysis of environmental management in Brazil. 1986. Tese (Doutorado) - University of Connecticut, Connecticut.

HANCE, B. J.; CHESS, C.; SANDMAN, P. M. Industry risk communication manual: improving dialogue with communities. Florida: Lewis Publishers, 1990.

JUNQUEIRA, L. (Org.). Desafios da modernização portuária. São Paulo: Aduaneiras, 2002.

LEIS, H. Um modelo político-comunicativo para superar o impasse do atual modelo político-técnico de negociação ambiental no Brasil. In: CAVALCANTI, C. (Org.). Meio ambiente, desenvolvimento sustentável e políticas públicas. São Paulo: Cortez/Recife: Fundação Joaquim Nabuco, 1999. 
LITTLE, P. Os conflitos socioambientais: um campo de estudo e ação política. In: BURSZTIN, M. (Org.). A difícil sustentabilidade - política energética e conflitos ambientais. Rio de Janeiro: Garamond, 2001.

MACHADO, P. A. L. Direito ambiental brasileiro. 3. ed. São Paulo: Revista dos Tribunais, 1991.

MAGANO, C. Proteção ambiental e a lógica dos negócios portuários. In: CUNHA, I. (Org.). Portos no ambiente costeiro. Santos: Leopoldianum, 2004.

MCKEAN M. A.; OSTROM, E. Regimes de propriedade comum em florestas: somente uma relíquia do passado? In: DIEGUES, A. C. S.; MOREIRA, A. C. C. Espaços e recursos naturais de uso comum. São Paulo: Nupaub-USP, 2001.

MEYER, H. City and port - transformation of port cities: London, Barcelona, New York, Rotterdam. Utrecht: International Books, 1999.

MIRANDA, L. B. O sistema estuarino de Santos. In: CÂMARA PAULISTA DO SETOR PORTUÁRIO. Memória técnica. São Paulo: Cetesb, 1996.

MORAES, A. C. R. Contribuições para a gestão da zona costeira do Brasil. São Paulo: Hucitec, 1999.

OLMOS, F. et al. Manguezais da Baixada Santista - uma área prioritária para a conservação da biodiversidade. In: CÂMARA PAULISTA DO SETOR PORTUÁRIO. Memória técnica. São Paulo: Cetesb, 1996.

PORTER, M.; VAN DER LINDE, C. Verde e competitivo. In: PORTER, M. Competição: estratégias competitivas essenciais. 3. ed. Rio de Janeiro: Campus, 1999.

RODRIGUES, F. et al. Os manguezais da Baixada Santista: uma proposta para classificação. In: CÂMARA PAULISTA DO SETOR PORTUÁRIO. Memória técnica. São Paulo: Cetesb, 1996.

RODRIGUES, J.; VAZ, J. Porto de Santos - uma década de transformações. Santos: Codesp/Unisanta, 2001.

SACHS, I. Estratégias de transição para o século XXI — desenvolvimento e meio ambiente. São Paulo: Studio Nobel/Fundap, 1993.

- Caminhos para o desenvolvimento sustentável. 2. ed. Rio de Janeiro: Garamond, 2002.

2004.

Desenvolvimento includente, sustentável, sustentado. Rio de Janeiro: Garamond, 
SCF (SUSTAINABILITY CHALLENGE FOUNDATION). 1st International Programme on the Management of Sustainability. The Netherlands: Nijenrode Business School, 1994. (Selected readings).

SUSSKIND, L.; FIELD, P. Em crise com a opinião pública. São Paulo: Futura, 1997.

—; LEVY, P.; THOMAS-LARMER, J. Negotiating environmental agreements. MIT — Harvard Public Disputes Program. Washington: Island Press, 2000. 